УДК $78.03+782.1$

DOI https://doi.org/10.31723/2524-0447-2020-30-2-30

Виктор Анатольевич Митюшкин

ORCID: 0000-0002-1198-9374

профессор кафедры сольного пения

Одесской национальной музыкальной академии

имени А. В. Неждановой

viktor.mityushkin2411@gmail.com

\title{
ТЕМБР-АМПЛУА КАК БИОЛОГИЧЕСКАЯ ХАРАКТЕРИСТИКА ГОЛОСОВОГО АППАРАТА И ТВОРЧЕСКИЙ ИНСТРУМЕНТ ОПЕРНОГО ПЕВЦА
}

Цель статьи - проанализировать тембр-амплуа оперного певца как природную биологическую характеристику голоса вокалиста и одновременно его творческий инструмент. Представить анализ видения тембра-амплуа оперного голоса с точки зрения автора музыкального материала, зрителя оперного спектакля, самого вокалиста. Определить взаимозависимость тембра-амплуа голоса и некоторых психофизических характеристик оперного певца. Методология статьи: сравнительный анализ, моделирование, анализ научной литературы по психологии личности, анализ феноменологии творческого процесса вокалиста в жанре оперы и специфики вокальной составляющей оперного искусства, логический анализ. Научная новизна состоит в том, что впервые представлен анализ феноменологии тембра-амплуа оперного певца с точки зрения автора музыкального материала, зрителя оперного спектакля, самого вокалиста. Дано обоснование ведущей роли тембра-амплуа вокалиста с точки зрения специфики сиенического существования оперного исполнителя. Тембр-амплуа рассмотрен как инструмент определения художественной семантики музыкального образа в опере и одновременно правдивого воплощения характера оперного персонажа на сиене. Представлена взаимозависимость тембра-амплуа вокалиста и его типа темперамента. Сила нервной системы оперного певиа обоснована как базовый критерий в прогнозировании профессиональной карьеры и специализации вокалиста. Выводы. Тембр-амплуа оперного певиа является биологической характеристикой его голосового аппарата и выступает в качестве инструмента расшифровки семантики музыкального образа и правдивого воплощения характера оперного персонажа на сцене. Определяющим фактором в реализации авторского замысла композитора, точного восприятия его зрителем и возможности успешного существования вокалиста в оперном спек-

(C) Митюшкин В. А., 2020 
такле является точное использование определенного тембра-амплуа применительно к определенным партиям. Тембр-амплуа вокалиста и тип его темперамента находятся в прямой зависимости. Сила нервной системы вокалиста является одним из важнейших базовых критериев в прогнозировании построения успешной карьеры и выбора творческой специализации певиа в труппе театра.

Ключевые слова: тембр-амплуа оперного певца, сила нервной системы, тип темперамента.

Mityushkin Victor Anatolyevich, Professor at the Department of Solo Singing of the Odessa National A. V. Nezhdanova Academy of Music

Timbre-role as a biological characteristic of the vocal apparatus and a creative instrument of an opera singer

The purpose of the article is to analyze the timbre-role of an opera singer as a natural biological characteristic of the vocalist's voice and, at the same time, his creative instrument. To present an analysis of the vision of the timbre-role of an operatic voice from the point of view of the author of musical material, spectator of an opera performance, and the vocalist himself. Determine the interdependence of the timbre-role of the voice and some psychophysical characteristics of the opera singer. Methodology of the article: comparative analysis, modeling, analysis of scientific literature on personality psychology, analysis of the phenomenology of the vocalist's creative process in the genre of opera and the specifics of the vocal component of opera art, logical analysis. The scientific novelty lies in the fact that the analysis of the phenomenology of the timbre-role of an opera singer from the point of view of the author of musical material, spectator of an opera performance, the vocalist himself is presented for the first time. The substantiation of the leading role of the vocalist's timbre-role is given from the point of view of the specifics of the stage existence of an opera performer. Timbre-role is considered as a tool for defining the artistic semantics of a musical image in an opera and at the same time as a true embodiment of the character of an opera character on stage. The interdependence of the vocalist's timbre-role and his type of temperament is presented. The strength of the nervous system of an opera singer is substantiated as a basic criterion in predicting the professional career and specialization of a vocalist. Conclusions. The timbre-role of an opera singer is a biological characteristic of his vocal apparatus and acts as a tool for deciphering the semantics of a musical image and a true embodiment of the character of an opera character on stage. The decisive factor in the implementation of the composer's author's intention, accurate perception of it by the viewer and the possibility of a successful existence of a vocalist in an opera performance is the precise use of a certain timbre-role in relation to certain parts. The timbre-role of the vocalist and the type of his temperament are in direct proportion. The strength of the vocalist's nervous system is one of the most important basic criteria in predicting the building of a successful career and the choice of a singer's creative specialization in a theater troupe.

Key words: timbre-role of an opera singer, strength of the nervous system, type of temperamen. 
Мітюшкін Віктор Анатолійович, професор кафедри сольного співу Одеської національної музичної академії імені А. В. Нежданової

Тембр-амплуа як біологічна характеристика голосового апарату та твориого інструменту оперного співака

Мета статmі - проаналізувати тембр-амплуа оперного співака як природну біологічну характеристику голосу вокаліста та одночасно його творчий інструмент. Представити аналіз бачення тембру-амплуа оперного голосу з точки зору автора музичного матеріалу, глядача оперної вистави, самого вокаліста. Визначити взаємозалежність тембру-амплуа голосу та певних психофізичних характеристик оперного співака. Методологія статті: порівняльний аналіз, моделювання, аналіз наукової літератури з психології особистості, аналіз феноменології творчого процесу вокалісту у жанрі опери та специфіки вокальної складової частини оперного мистецтва, логічний аналіз. Наукова новизна полягає у тому, що вперше представлено аналіз феноменологіі тембру-амплуа оперного співака з точки зору автора музичного матеріалу, глядача оперної вистави, самого вокаліста. Дано обгрунтування провідної ролі тембру-амплуа вокаліста з точки зору специфіки сиенічного існування оперного виконавия. Тембр-амплуа розглянуто як інструмент визначення художньої семантики музичного образу в опері та одночасно правдивого втілення характеру оперного персонажа на сцені. Представлено взаємну залежність тембру-амплуа вокаліста та його типу темпераменту. Силу нервової системи оперного співака обгрунтовано як базовий критерій у прогнозуванні професійної кар'єри та спеціалізації вокаліста. Висновки. Тембр-амплуа оперного співака $\epsilon$ біологічною характеристикою його голосового апарату та виступає як інструмент розшифрування семантики музичного образу та правдивого втілення характеру оперного персонажа на сцені. Визначальним фактором у реалізації авторського задуму композитора, вірного сприйняття його глядачем та можливості успішного існування вокаліста у оперній виставі є точне використання певного тембру-амплуа стосовно певних партій. Тембр-амплуа вокаліста та тип його темпераменту перебувають у прямій залежності. Сила нервової системи вокаліста $\epsilon$ одним з базових критеріїв у прогнозуванні побудови успішної кар'єри та вибору творчої спеціалізації співака у трупі театру.

Ключові слова: тембр-амплуа оперного співака, сила нервової системи, тип темпераменту.

Актуальность исследования. Для того чтобы наглядно пояснить специфику рождения певцом музыкального образа в опере, необходимо понимание феноменологии самого жанра с точки зрения исполнительского аспекта. На наш взгляд, основу исследования этой проблемы следует искать в понимании самой поэтики жанра оперы.

В научной литературе представлено огромное число определений термина «поэтика» применительно не только к лите- 
ратуре, но и другим творческим жанрам. В контексте темы статьи фокус нашего внимания обрашен на понимание поэтики оперы как «сочетания выразительных средств, которое делает художественное произведение гармоничным и заставляет осознавать мир автора» (И.А. Нестерова) [5]; а также на понимание поэтики как связи языка (средства коммуникации) и сознания (А.А. Потебня).

В этом контексте попытаемся охарактеризовать тембр-амплуа вокалиста как основной инструмент расшифровывания авторского замысла и его успешного воплощения в жанре оперы, представить специфику сценического существования вокалиста в опере и объяснить природную связь тембра-амплуа оперного вокалиста и некоторых его психофизических характеристик.

Объяснение этой связи необходимо для понимания принципов специализации вокалиста и определения характера персонажа в оперном материале. А также для успешного диагностирования и прогнозирования творческой карьеры вокалиста.

Цель статьи - проанализировать тембр-амплуа оперного певца как природную биологическую характеристику голоса вокалиста и одновременно его творческий инструмент. Представить анализ видения тембра-амплуа оперного голоса с точки зрения автора музыкального материала, зрителя оперного спектакля, самого вокалиста. Определить взаимозависимость тембра-амплуа голоса и некоторых психофизических характеристик оперного певца.

Научная новизна состоит в том, что впервые представлен анализ феноменологии тембра-амплуа оперного певца с точки зрения автора музыкального материала, зрителя оперного спектакля, самого вокалиста. Дано обоснование ведущей роли тембра-амплуа вокалиста с точки зрения специфики сценического существования оперного исполнителя. Тембр-амплуа рассмотрен как инструмент определения художественной семантики музыкального образа в опере и одновременно правдивого воплощения характера оперного персонажа на сцене. Представлена взаимозависимость тембра-амплуа вокалиста и его типа темперамента. Сила нервной системы оперного певца обоснована как базовый критерий в прогнозировании профессиональной карьеры и специализации вокалиста. 
Изложение основного материала. Итак, жанр оперы предполагает коммуникацию особого характера, в некотором смысле не требующую когнитивной работы, а изначально заточенную таким образом, что зритель на подсознательном уровне воспринимает и угадывает сценическое действие благодаря богатству красок человеческого голоса.

Оперный певец характеризуется особым типом голосовых данных, позволяющих развить голос до определенного диапазона, и определенным уровнем звуковой эмиссии, позволяющим оркестровое сопровождение голоса без звуковых потерь. Иными словами, голос оперного певца должен иметь определенные диапазонные характеристики, определенные эмиссионные характеристики, а также определенные тембральные характеристики, соответствующие общепринятой типологии голосов.

Касательно тембральных характеристик оперного голоса следует отметить, что жанр оперы диктует обязательную выраженную принадлежность вокалиста к определенному типу голоса и определенному тембру-амплуа. Это объясняется тем, что все оперные партии имеют очень узкий «коридор исполнителей»: оперная партия может быть качественно реализована только определенным типом голоса, точнее, определенным тембром-амплуа определенного типа голоса. По мнению Е. Авраменко, «тембр-амплуа способен в вокальном отображении полноценно выразить семантику характера оперного персонажа, «опредмечивает» в вокальном звуке тип личности героя и способ его художественного мышления...» [1, с. 90].

Композитор сочиняет музыкальную партитуру оперного образа исходя из того, что исполнитель этой партии будет обладать строго определенными качествами голоса - высотным типом: сопрано, меццо-сопрано, контральто, тенор, баритон, бас; и выраженным тембром-амплуа, именно тем, который автор мыслит для воплощения художественной и музыкальной задачи образа в общем контексте произведения.

Касательно типа голоса, партитура оперного образа рассчитана на определенную тесситуру исполнения, максимальное использование диапазона заявленного типа голоса (особенно это касается ролей первого плана), определенную эмиссионную силу данного типа голоса, чтобы «пробить» оркестровую партитуру.

Но тембр-амплуа - своеобразный «подтип» типа оперного голоса - является уже «куратором» художественных задач 
оперного спектакля. Опираясь на немногочисленные исследовательские обращения к феномену тембра-амплуа оперного певца как определенного инструмента выразительности в жанре, а также многолетнего исполнительского опыта работы в оперном театре, предлагаем триединое видение функционального предназначения тембра-амплуа оперного вокалиста в процессе реализации художественных задач в жанре оперы. Тембр-амплуа является:

- для автора - точной художественно-звуковой краской в общей палитре произведения;

- для зрителя - определенным типом характера сценического персонажа (лирический, драматический, характерный);

- для вокалиста - физическими и психофизиологическими характеристиками его аппарата, которые он знает и, в соответствии с которыми, пользуется своим вокальным аппаратом.

Разберем последовательно эти три позиции, касающиеся тембра-амплуа вокалиста.

В оперном искусстве, как особом жанре, с одной стороны, воплощается высшая степень условности сценического действа - пение вместо речи, а с другой - опера является полем очень «жестко-очерченного» понимания характеров персонажей и, соответственно, трактовки драматургического конфликта. Такое жесткое очерчивание «поля маневра» для постановщиков и исполнителей определяет музыкальный материал. Режиссеру оперного спектакля музыкальная атмосфера и музыкальная партитура не дают возможности вольно трактовать драматургию произведения. Музыка «консервирует» понимание и общепринятую трактовку оперного материала, т.к. именно вокалисты, которые являются воплотителями музыкальных образов, не могут иметь иной тип голоса, нежели это предусмотрено автором произведения. Более того, драматический баритон не может петь партию лирического баритона - «краска» персонажа в общей музыкальной палитре должна быть строго определенной, и эту краску может воплотить голос строго определенной тембральной характеристики. Таким образом, соответствие не только типа голоса, но и тембра-амплуа вокалиста авторскому видению определенной партии является главным условием назначения его на эту партию и, в конечном итоге, общей успешности спектакля.

Следует заметить, что тембр-амплуа играет также определяющую роль в зрительском восприятии персонажа. Тем- 
бральные краски голоса вокалиста сразу настраивают зрителя на определенное восприятие музыкального образа: если это лирический голос, то зритель сразу чувствует, что персонаж имеет характер мягкий, скорее всего в драматургическом развитии он будет воплощать любовную линию, линию молодых чувств, юного восприятия жизни, беззащитности перед трудностями и т.п. Если же зритель слышит тембральный краски драматического голоса, он подсознательно готовится к конфликтной ситуации, к страданиям героя, к борьбе, к восприятию героя как негативного персонажа - злодея и т.п. Первозданность, архетипность такого подсознательного восприятия тембральных красок человеческого голоса имеет очень много описаний и обоснований в науке и в популярной литературе и даже в вокальных методиках. Эта тема требует огромного и подробного отдельного рассмотрения. Сейчас для нас важным является то, что тембральные краски голоса вокалиста безошибочно программируют зрительское восприятие.

Следует отметить также, что так называемые «промежуточные» голоса - mittelstimme - в опере менее конкурентноспособны, нежели голоса выраженной принадлежности по типу и по тембру-амплуа. Поле применения «промежуточных» голосов в опере гораздо уже, чем у их «определенных» собратьев. А в камерном вокальном искусстве - наоборот. Менее выраженная «типажность» голоса дает более широкое поле для трактовки музыкального материала. В камерном вокальном искусстве певец находится в более «благоприятных» условиях: эмиссионные требования к исполнителю уходят на дальний план, т.к. «слышимость» певца - результат скоординированной работы с концертмейстером, который должен учитывать характеристики голоса своего солиста и корректировать «плотность» подачи аккомпанемента. Кроме того, в камерном пении больший успех имеют голоса «неясного» тембра-амплуа, т.к. такая неясность дает возможность певцу работать над совершенно разным материалом и даже в рамках одного произведения позволяет использовать гораздо большую палитру исполнительских красок.

Согласно концепции автопоэзиса живых систем, направление и успешность развития системы определяют ее биологические характеристики.

К биологическим природным данным вокалиста относятся не только описанные физиологические качества голоса, но 
и психофизиологические характеристики певца-личности, такие как тип темперамента и сила нервной системы, которые для построения карьеры певца в опере играют немаловажную роль [6, с. 50].

Тип темперамента для солиста оперы, на наш взгляд, имеет более важное и неожиданное значение, нежели в любом другом сценическом виде искусства. Оперное искусство по самой своей сценической природе «условности происходящего» является театральным, т.е. требующим некоей «маски» - превращения исполнителя в образ, отличный от личности певца. Но в опере перерождение личности артиста в личность персонажа, по сравнению с драматическим театром или театром мюзикла является весьма условным. В драме и мюзикле актер, перерождаясь, моделирует свой тембр голоса (причем не всегда сознательно). В опере тембр голоса основная музыкальная краска персонажа - неизменен. Специфика коммуникации жанра предполагает, что образ проявляет в опере не актерская «маска», а голос певца - его «живой инструмент». А голос, как физиологические природные данные, изменить невозможно. Таким образом, инструментом создания музыкального образа - некоей «оперной маски» является тембр голоса певца, который всегда один и тот же. То есть тип голоса, тембр голоса и личность певца (которая не испытывает «актерское» перерождению в иную личность) не подвергаются трансформации, свойственной, скажем, психофизическому аппарату актера драматического театра или артиста мюзикла. И тип голоса, и тембр голоса, и манера пения, и личностные проявления исполнителя в опере - это константные составляющие.

Отсюда вывод - «маска» сценического образа должна максимально совпадать с психофизикой исполнителя (иначе просто художественный замысел композитора не может быть воплощен).

Иными словами, музыкальный образ должен максимально совпадать с характеристиками личности вокалиста. Произведение не имеет успешного воплошения, если тип темперамента исполнителя не отвечает задачам музыкального образа. А сам музыкальный оперный образ постоянен, не подвержен изменениям трактовки. Само решения спектакля может быть парадоксальным, но типичность вокально-сценического образа не изменится - в рамках музыкальной партитуры это 
просто невозможно, т.к. тесситура вокальной линии, плотность оркестровки и т.П. специфика музыкального материала не позволяет другому типу голоса (даже другому тембру-амплуа этого же типа голоса) убедительно прозвучать в данном материале. Иными словами, для воплощения вокальной партии необходим только определенный тип голоса и только определенного тембра-амплуа. Попытки отступления от этого правила ломают всю конструкцию конкретного оперного произведения и нарушают «правила коммуникации» оперного театра как особого жанра сценического искусства.

Таким образом, если «огрубить» проблему - для героев трагических, драматических необходим вокалист с сильным типом темперамента, а для героев лирических возможен более «мягкий» тип. А в опере образы драматические реализуют голоса драматического тембра-амплуа, лирические соответственно. Таким образом, можно сделать вывод о том, что тембр-амплуа вокалиста в некотором смысле является проекцией его психотипа в музыке, как в театре драматическом проекцией психотипа актера является его амплуа. Если в драматическом театре успех воплощения сценического образа прогнозирует амплуа актера, в оперном театре эту неуловимую, но очень важную характеристику несет тембр-амплуа певца. В отличие от артистов мюзикла, для которых возможны расширения тембральной палитры голоса (за счет использования микрофона и законов жанра, имеющего иные приоритеты и средства коммуникации), для оперного певца практически невозможен выход за рамки тембральной палитры своего типа голоса (тончайшая нюансировка и оперная «Поверх-оркестровая» эмиссия звука - несовместимы). Следовательно, оперный певец всегда пребывает в узких рамках своего типа голоса и своего тембра-амплуа. Иными словами, можно утверждать, что тембр-амплуа в определенном смысле ограничивает творческий потенциал конкретного певца.

Уточним, если в опере тип голоса - сопрано, меццо-сопрано, тенор, баритон и т.п. - несет общий контур образа, то тембр-амплуа выступает как развернутая психологическая характеристика общего типа в конкретном контексте - музыкальном произведении. Тембр-амплуа, на наш взгляд, своеобразное «психологическое клеймо» персонажа в опере.

В академическом сообществе в процессе воспитания вокалистов ранжирование голосов идет по физиологическим 
характеристикам - диапазон, плотность наполнения, эмиссия звука и т.п. Но часто выпускается из виду такая важная характеристика голоса, как тембр-амплуа, определение и анализ которого начинается не только с физиологических характеристик голоса, но и с оценки темперамента будущего оперного певца.

Изучая феномен тембра-амплуа оперного голоса, на наш взгляд, следует рассматривать голосовые данные вокалиста с точки зрения автопоэзного подхода, как результат сплетения всех характеристик организма певца - наличия вокального голоса - физиологических данных, а также и природных качеств, характеризующих психические процессы. В частности, в тембре-амплуа опосредовано отражен тип темперамента вокалиста. Иными словами, окраска голоса, в определенном смысле, выступает как внешнее проявление скорости и интенсивности внутренних процессов певца.

Причем следует учесть, что голос - это «живой инструмент», и он реагирует на мысли, чувства и т.п. внешние раздражители быстрее, чем сам вокалист может это осознать. Иначе говоря, для успешности воплощения авторского замысла тип темперамента (как отражение скорости и интенсивности реакции организма на окружающую среду) у вокалиста и его персонажа должны максимально совпадать.

Также следует учитывать то обстоятельство, что на сцене оперный вокалист - артист «без маски» - противостоит тысячному залу. А чтобы это неравное противостояние эмоционально не уничтожило артиста, его тип нервной системы должен быть очень сильным.

Ф.-Ж. Тальма в "Reflexion sur Lekain" так объяснял уникальность нервной организации артиста: «Актер должен быть одарен от природы организацией особого рода. Ибо понятно, что человек, предназначенный изображать страсти в высочайшем их напряжении, во всем их неистовстве, должен обладать исключительной энергией» [цит. по: 2].

Добавим от себя, что сила нервной системы вокалиста, на наш взгляд, должна быть более сильной, чем даже у актера. Ведь вокалист на сцене «Я в предлагаемых обстоятельствах», иными словами, ему не помогает «маска», то есть неоткуда взять дополнительные эмоции и не за чем спрятаться. В отличие от актера, природа творчества которого позволяет черпать из состояния «не-Я» - состояния «маски» дополнительные 
энергетические резервы, сама природа оперного искусства не позволяет спрятаться за «маску» - тембр-амплуа выдает истину. Кроме того, как уже говорилось, эмиссионно-звуковые требования к оперному исполнению не позволяют «расслабиться» в полутонах эмоций. Всегда «повышенная звучность» голоса порождает у певца повышенную экспрессивность существования на сцене. К слову, именно поэтому некоторые критики называют оперный театр катурновым приподнятым над реальностью, слишком условно-театральным. А эта черта - результат самой природы оперного пения, результат специфики психологического существования оперного певца в творческом процессе.

Кроме того, силой нервной системы определяются и такие карьерные категории как статусное положение в труппе. Психолог В.И. Рождественская утверждает, чти тип слабой нервной системы наиболее эффективно проявляет себя в монотонном режиме работы, а тип сильной нервной системы наиболее эффективно работает в режиме стрессового напряжения [7].

В оперном театре в режиме максимального стрессового напряжения находятся исполнители главных партий, меньшую нагрузку испытывают исполнители «моржовых партий» - партий второго плана и наименее сильный тип нервной системы востребован в хоре. Это ранжирование подтверждают многочисленные примеры из жизни. Есть немало певцов с уникальными голосами, которые поют в хоре. Чем это объяснить? На наш взгляд, это объясняется слабым типом их нервной системы. Существование на сцене в «щадящем» энергетическом режиме для них более комфортно, чем работа в главной партии, требующая огромной экспрессии и стрессоустойчивости.

В.Д. Небылицын акцентирует на том, что понятие темперамента лишено всякого смысла, если в него не включить особенности форм поведения, иначе, ни одно психическое свойство не может рассматриваться как простое отражение физиологических свойств нервной системы [4, с. 134].

В рамках темы нашего исследования это утверждение дает, хоть и косвенное, но подтверждение природной связи и взаимозависимости физиологической основы личности певца его голоса, и его психических свойств, которые, на наш взгляд, отражены в «психологической природе» голоса - тембре-амплуа, основанном на звуковых предпочтениях, рожденных не 
только спецификой аппарата, но и обусловленных его психо-эмоциональной составляющей.

По мнению К. Леонгардта, именно тип темперамента определяет темп и глубину эмоциональных реакций исполнителя [3]. Учитывая то, что оперный певец на сцене выступает от своего имени, а не от имени «маски», тип темперамента певца отражается в его тембре-амплуа. Акцентируем, не в типе голоса, а именно в тембре-амплуа. В свою очередь, такая определенность тембра-амплуа априори предполагает совершенно определенный тип темперамента певца.

Тембр голоса вокалиста является инструментом индивидуализации и персонификации сценического образа, иными словами, в оперном искусстве музыкальный образ рождается благодаря именно тембру-амплуа [1, с. 93]. Заметим, что в опере типология тембра-амплуа основывается на принципах экспрессивности и натуральности голосов [9, с. 37], что в какой-то мере является воплощением в жанре оперы принципов реалистического психологического театра.

Именно тембр-амплуа «опредмечивает» в звуке тип личности персонажа. Но тембр-амплуа, как и тип голоса, изменить невозможно. Соответственно, перефразируем известное выражение: «Скажи мне свой тембр-амплуа - и я скажу, какой у тебя темперамент» и наоборот.

Речь идет о состоявшихся оперных певцах. Многолетний педагогический опыт дает право утверждать, что несовпадение природных физиологических характеристик голоса и типа темперамента (такое случается) не позволяет говорить о карьере солиста. Певец с таким «несовпадением» просто не сможет выдержать эмоциональную и техническую нагрузку музыкального материала для своего типа голоса и тембра-амплуа. Голосовой аппарат, как живой инструмент, не может полноценно озвучить свой тембр, не имея соответствующей эмоциональной подпоры.

Также интересным и показательным является то, что, несмотря на утверждение К. Леонгардта о том, что творческим личностям более присущ интровертный тип личности [3], утверждаем, что оперным певцам присущ именно экстравертный тип личности. Это связано не только с тем, что сценическая деятельность требует коммуникативности и способности коммуницировать, но и с жанровой поэтикой оперного театра, а именно с тем, что опера - это не реалистиче- 
ский театр, а скорее условно-символический (даже в бытовых сюжетах). Сама природа оперного искусства - распевание-растягивание во времени проживания эмоции, отсутствие «маски» как результата перерождения личности певца в личность персонажа и т.п. специфические особенности жанра требуют повышенного эмоционально-энергетического запаса исполнителя (хотя бы для того, чтобы попытаться в сольном номере в условиях «растягивания во времени проживаемой эмоции» удержаться на пике переживания). Следует заметить, что такой энергетический запас певцу дает интровертная составляющая его личности, которая имеет свою специфику. Львиная доля интровертности оперного певца направлена не на переживание музыкально-драматургического материала, а на «погружение» в собственный звук. С одной стороны, такое «погружение» несколько обедняет когнитивный процесс певца, но с другой - именно в этом погружении раскрывается феноменология оперного пения. Чувствование певца включается более физиологическим ощущением тембральных красок собственного голоса, нежели интонационной семантикой музыкального материала. Голос певца является уникальным живым инструментом. Ощущение собственного голоса, чувствование его тембра полностью подчиняют себе весь алгоритм существования в музыкальном материале.

Выводы. Тембр-амплуа оперного певца является биологической характеристикой его голосового аппарата и выступает в качестве инструмента расшифровки семантики музыкального образа и правдивого воплощения характера оперного персонажа на сцене. Определяющим фактором в реализации авторского замысла композитора, точного восприятия его зрителем и возможности успешного существования вокалиста в оперном спектакле является точное использование определенного тембра-амплуа применительно к определенным партиям. Тембр-амплуа вокалиста и тип его темперамента находятся в прямой зависимости. Сила нервной системы вокалиста является одним из важнейших базовых критериев в прогнозировании построения успешной карьеры и выбора творческой специализации певца в труппе театра.

\section{СПИСОК ЛИТЕРАТУРЫ}

1. Авраменко Є.Б. Тембр-амплуа як інструмент вираження оперного «голосообразу» (на прикладі драматичного тенора). Музичне мистецтво у культура: науковий вісник ОНМА імені А.В. Нежданової / 
гол.ред. К. Фламм. Вип. 30(1). Одеса : Видавничий дім «Гельветика», 2020. С. 89-96.

2. Гуревич Л.Я. Творчество актера: О природе художественного переживания актера на сцене : Опыт разрешения векового спора. Москва : ГАХН, 1927. 62 с.

3. Леонгардт К Акцентуированные личности / пер с нем. ; предисл. и ред. В.М. Блейхер. 2-е изд.стер. Київ : Вища школа, Головное изд-во, 1989. 375 с.

4. Небылицын В.Д. Психофизиологическое исследование индивидуальных различий. Москва : Наука, 1976. 335 с.

5. Нестерова И.А. Поэтика художественного произведения // Энциклопедия Нестеровых. URL : http://odiplom.ru/lab/poetikahudozhestvennogo-proizvedenija.html (дата обращения: 28.03.2020).

6. Оганезова-Григоренко О.В. Автопоэзис артиста мюзикла как творческий феномен и предмет музыковедческого дискурса : монография. Одесса : Астропринт, 2019. 376 с.

7. Рождественская В.И. Небылицын В.Д., Борисова М.Н. и др. Сравнительное изучение различных показателей силы нервной системы человека. Вопросы психологии. 1960. № 5. 182 с.

8. Тан Чжанчен Специфика трактовки баса в опере XVIIXIX веков: между амплуа и характером : дисс. канд. искуст-я, 17.00.03 - музыкальное искусство. Харьков, 2017. 216 с.

\section{REFERENCES}

1. Avramenko E. (2020) Timbre-role as an instrument of expression of opera "voice image" (on the example of dramatic tenor) // Musical art in culture: scientific bulletin of ONMA named after A.V. Nezhdanova / ed. K. Flamm. Vip. 30 (1). Odessa. Helvetica Publishing House. [in Ukrainian]

2. Gurevich L. (1927) Creativity of an actor: On the nature of an actor's artistic experience on stage: An experience of resolving a centuryold dispute. M.: GAKhN. [in Russian]

3. Leonhardt K. (1989) Accentuated personality. K, Vishcha school, Head publishing house. [in Ukrainian]

4. Nebylitsyn V. (1976) Psychophysiological study of individual differences. M.: Nauka. [in Russian]

5. Nesterova I. Poetics of a work of art // Encyclopedia of the Nesterovs. URL: http://odiplom.ru / lab / poetika-hudozhestvennogoproizvedenija.html (date accessed: 03/28/2020)

6. Ohanezova-Hrihorenko O. (2019) Autopoiesis of a musical artist as a creative phenomenon and subject of musicological discourse: monograph. Odessa: Astroprint. [in Ukrainian]

7. Rogdestvenskaya V., Nebylitsyn V., Borisova M. et al. (1960) Comparative study of various indicators of the strength of the human nervous system // Questions of psychology. No. 5.. [in Russian]

8. Tan Chganchen (2017) The specifics of the interpretation of bass in the opera of the XVII-XIX centuries: between the role and character. Candidate degree of Arts : 17.00.03. Kharkov. [in Ukrainian] 